\title{
Establishment of a Cell Line in vitro from the Lesion of a Clinical Case of Penis Cancroid
}

\author{
Isao Yamane and Tatsunori Tsuda \\ Microbiology Division, Research Institute for Tuberculosis, \\ Leprosy and Cancer, Tohoku University, Sendai
}

\begin{abstract}
A cell line in vitro has been successfully established from the lesion of a clinical case of penis cancer which was histologically diagnosed as squamous cell carcinoma. The primary culture from the lesion was performed by means of explant culture method and the concomitant outgrowth of both epithelial and fibroblastic cells were observed at the early stage of the culture. But the fibroblastic cells were missed in 6 months after the culture onset and only the epithelial cells were transferred up to the present time (July, 1965) for about three years. The epithelial cells showed typical epithel shape and pavement-like arrangement to one another. As to the chromosomal structure of the present cell line, the 12 month culture showed bimodal distribution which had two modal peaks at 46 and 52 and thereafter they moved to one peak of 52 and further to 50 . The result of the karyotype analysis showed the cell line contained abnormal chromosome. When the culture was implanted to the cheek pouches of the cortisonetreated Syrian hamsters, the inoculation of $10^{4}$ cells did not induce any nodular growth in hamster cheek pouches but the inoculation of $10^{6}$ cells induced the growth in two of seven animals tested and $10^{7}$ cells induced the lesion in all animals tested, respectively.
\end{abstract}

Since an attempt was undertaken by Gey et al. ${ }^{1}$ to culture human cancer cells in vitro and to study their nature, many cell lines originating from human tumor tissues have been reported. In the authors' laboratory also, two cell lines of human tumor origin were established so far: one originated from a case of lung cancer $^{2}$ and the other from ascites of reticulosarcomatosis. ${ }^{3}$ Further now one cell line has been established in vitro which originated from the lesion of human penis cancer diagnosed as squamous cell carcinoma. The present report deals with the process to its establishment, the morphology of the established cell line, chromosomal constitution and the investigation on its malignancy.

\section{MATERIALS AND METHODS}

Specimen: A part of the resected lesion from a case of penis cancer was employed as a specimen. The lesion was diagnosed histologically as squamous cell carcinoma. The specimen was dissected with scissors into pieces of about

Received for publication, September 3, 1965 
$1 \mathrm{~mm}^{3}$ and explanted into two square culture bottles $\left(8 \times 4.5 \times 4.5 \mathrm{~mm}^{3}\right)$.

Culture medium: A modified Eagle's culture mdium ${ }^{4}$ supplemented with $20 \%$ bovine serum was employed throughout the present work. Besides, $60 \mathrm{mg}$ of kanamycin was added to one liter of the medium as a decontaminant.

Cultural procedure: All the culture was incubated at $37^{\circ} \mathrm{C}$, and the culture medium was renewed every two or three days except in cases specially noticed. The procedure of subculture was carried out at the time of confluent cellular growth. The cell dispersion fluid was a mixed solution composed of $0.025 \%$ pronase $^{5}$ (a commercial protease preparation from a Streptomyces, Kakenkagaku Co., Tokyo), 0.02\% EDTA, and 0.01\% Methocel which were dissolved in Hanks' physiological fluid. The above cell dispersion fluid was added to the confluent culture and incubated at $37^{\circ} \mathrm{C}$ for 10 minutes to liberate the cells from bottle wall and disperse them. After the dispersed cells were centrifuged down to separate them from the dispersion agent, they were distributed into two culture bottles and added with $5 \mathrm{ml}$ of the culture medium and incubated at $37^{\circ} \mathrm{C}$.

Morphological study: The cultures grown over pieces of cover glass were employed for histological study. They were at first rinsed with Hanks' fluid and fixed with absolute methanol and stained with Giemsa solution. For chromosomal analysis, the cells were incubated in the medium added with $10^{-7} \mathrm{Mol}$ of colchicine for 8 hours. Then the cells were liberated from the bottle wall with the use of the foregoing cell dispersion fluid and suspended in 1/6 strength of Hanks' solution at $37^{\circ} \mathrm{C}$ for 30 minutes. Thus hypotonic-treated cells were stretched over slide strips, following Siminovitch and Rothfels' air drying technique ${ }^{6}$ and stained with Giemsa solution.

Transplantation test: Following Folley and Handler's method ${ }^{7,8}$ the cultured cells were implanted to the cheek pouches of Syrian hamsters treated with cortisone acetate and nodule formation at the site of implantation was checked every day after the inoculation.

\section{RESULTS}

Process up to the cellular establishment: The primary culture was carried out on July 28, 1962, with the use of the explants of the tumor tissue diagnosed as squamous cell carcinoma (Table 1). In the early stage of the culture, abundant fibroblastic cells migrated from the explants and proliferated there. After about 40 days in vitro, epithelial cells began to migrate, following the outgrowth of fibroblastic cells, and after about 60 days in vitro epithelial cells conspicuously multiplied. The first culture transfer was performed with the use of a mixed solution of $0.05 \%$ trypsin, $0.02 \%$ EDTA, and $0.01 \%$ Methocel 72 days after the initial culture. With this solution, the great majority of fibroblastic cells were liberated from the bottle wall, whereas epithelial cells remained 
TABLE 1. Culture history

\begin{tabular}{c|c|c|r|r|r}
\hline \multicolumn{3}{c|}{ Epithelial cells } & \multicolumn{3}{|c}{ Fibroblastic cells } \\
\hline $\begin{array}{c}\text { No. of } \\
\text { transfers }\end{array}$ & $\begin{array}{c}\text { Duration } \\
\text { (days) }\end{array}$ & $\begin{array}{c}\text { Culture days } \\
\text { in total }\end{array}$ & $\begin{array}{c}\text { No. of } \\
\text { transfers }\end{array}$ & $\begin{array}{c}\text { Duration } \\
\text { (days) }\end{array}$ & $\begin{array}{c}\text { Culture days } \\
\text { in total }\end{array}$ \\
\hline 1 & & & 1 & & \\
2 & 86 & & 2 & 72 & \\
3 & 13 & 99 & 3 & 5 & 79 \\
4 & 10 & 109 & 4 & 5 & 86 \\
5 & 10 & 119 & 5 & 6 & 92 \\
6 & 7 & 126 & 6 & 5 & 99 \\
7 & 7 & 133 & 7 & 5 & 104 \\
8 & 6 & 139 & 8 & 6 & 110 \\
9 & 7 & 146 & 9 & 6 & 116 \\
10 & 8 & 154 & 10 & 5 & 121 \\
11 & 6 & 160 & 11 & 6 & 127 \\
12 & 7 & 167 & 12 & 5 & 132 \\
13 & 6 & 173 & 13 & 7 & 139 \\
14 & 6 & 179 & 14 & 7 & 146 \\
15 & 5 & 184 & 15 & 6 & 152 \\
16 & 6 & 190 & 16 & 7 & 159 \\
17 & 5 & 195 & 17 & 12 & 171 \\
18 & 5 & 200 & $18+$ & & 182 \\
19 & 4 & 204 & & 46 & 218 \\
20 & 5 & 209 & & & \\
21 & 4 & 213 & & & \\
22 & 3 & 216 & & & \\
23 & 4 & 220 & & & \\
24 & 3 & 223 & & & \\
25 & 4 & 227 & & & \\
$26 *$ & 3 & 330 & & & \\
& 4 & 234 & & & \\
\hline
\end{tabular}

* Epithelial cells showed stable growth after that.

† Fibroblastic cells began to degenerate and finally disappeared.

attached to the bottle wall. Therefore, a similar treatment was undertaken again in further cultures and fibroblastic cells were completely liberated from the bottle wall. As the results of these treatments fibroblastic cells were isolated from epithelial cells and both kinds of cells could be cultured separately thereafter. The optimal condition to liberate the epithelial cell from the bottle wall was pursued in detail and it was proved that epithelial cells were completely liberated from the bottle wall by the incubation at $37^{\circ} \mathrm{C}$ for 10 minutes in a mixed solution of $0.025 \%$ pronase, $0.02 \%$ EDTA, and $0.01 \%$ Methocel.

Since then, the treatment for the culture transfer of the epithelial cells was carried out once or twice a week with the use of the above condition. Also, the transfer of fibroblastic cells was performed along the similar line. But fibroblastic cells could not grow after the 18th transfer which was made 6 months after the initial culture, and began to degenerate and finally disappeared 46 days after that. On the other hand, epithelial cells showed quite stable growth since then and even more accelerated growth later. So the subsequent studies were 


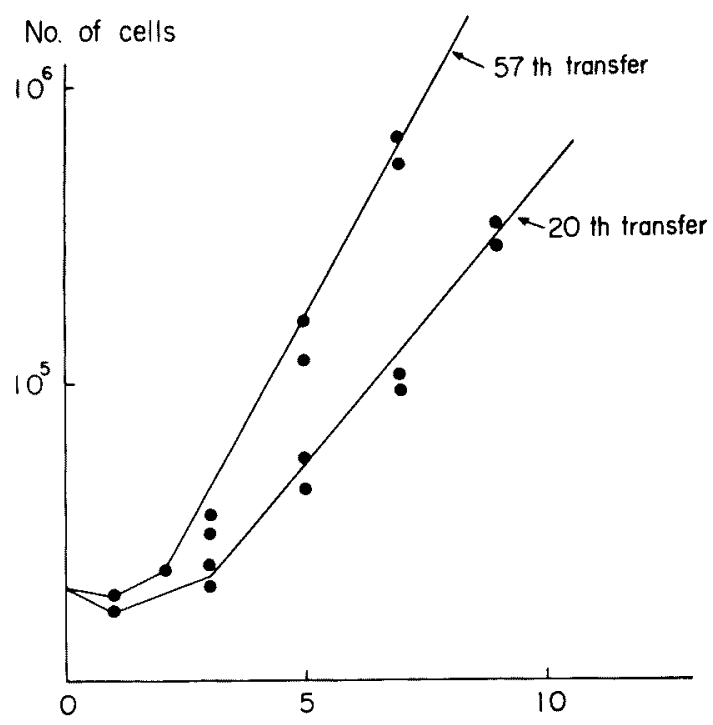

Fig. 1. Growth curve of PK cells.

made with the use of the epithelial cells designated PK cell line.

Growth rate: The culture at the 20 th transfer $(7$ months after the culture onset) delivered a cellular harvest 6 times of its inoculum size after one week incubation, while the culture at the 57th transfer (12 month after the primary culture) a cellular harvest 25 times of its inoculum size (see Fig. 1). Besides, the culture at the latter transfer could be initiated from an inoculum size as small as 100 cells per $\mathrm{ml}$ medium.

Cell morphology: As shown in Fig. 3, the cells had typical epithelial shape with round or oval nuclei. They had often more than one nucleus in one cell, while fibroblastic cells with two or more nuclei were not observed. The electron-micrograph of the epithelial cells demonstrated irregular-shaped nuclei and microvilli on their surface (see Fig. 7).

Chromosomal study: More than one hundred cells were examined for the study of chromosome constitution. The first cell sampling was made 12 months after the primary culture and the results of the chromosomal analysis at that time revealed that the cell population had bimodal peaks, one at diploid chromosomal number of 46 and the other at hyperdiploid number of 52, and a few cells with the chromosome number of tetraploid range were observed (see Fig. 2). The second sample was taken 20 months after the culture onset. The results of the analysis this time revealed that the former peak at the diploid number was extinct and a unique peak appeared in the hyperdiploid range ( 52 chromosomal number) and $49 \%$ of the total population was concentrated around the latter peak. The 

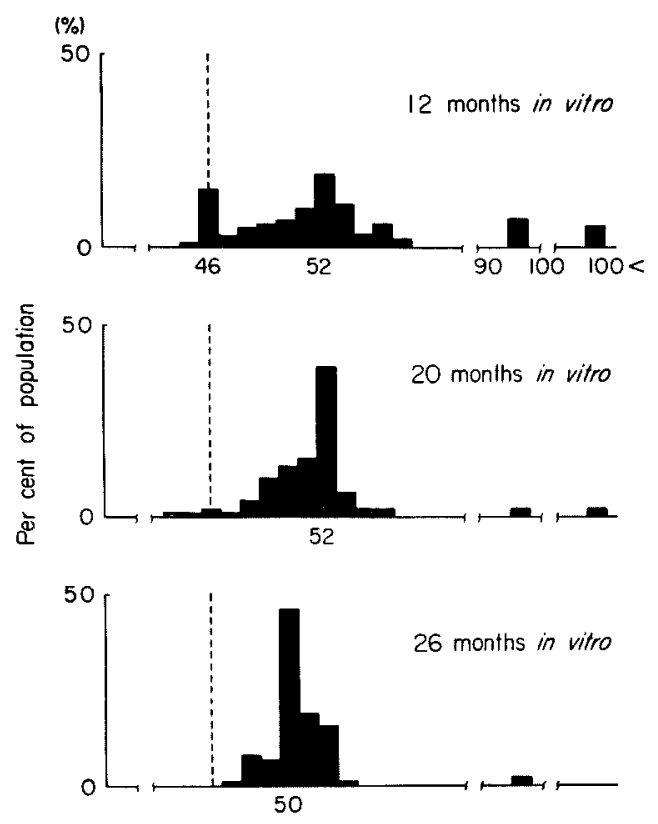

Chromosome count

Uiploid count

Fig. 2. Distribution of chromosome number classes in populations of PK cells.

third sampling was made in 26 months after the culture initiation. The modal number of the cell population had shifted from 52 to 50 , and $56 \%$ of the total population was concentrated around the peak. As to the classification of karyotype, the authors followed the formula proposed by the Denver group. Referring to the above formula, 2 abnormal chromosomes absent in normal human cells were always found in the present cell population so long as the authors examined it after 12 and 25 months in vitro: the one was the largest metacentric chromosome belonging to $\mathrm{A}$ group and the other was the largest telocentric belonging to $\mathrm{D}$ group (see Figs. 5 and 6). Also, the chromosomes with dicentric constriction were sometimes observed. Compared with the chromosomal numbers of each group found in the normal karyotype, those of $A$ and $G$ groups in the present cells, respectively, increased and those of $D$ and $G$ groups decreased, while those of $\mathrm{B}$ and $\mathrm{E}$ groups sometimes increased and in other times decreased and they showed no consistent transition (see Table 2). 
TABLE 2. Chromosome constitution of 17 metaphases of PK cells

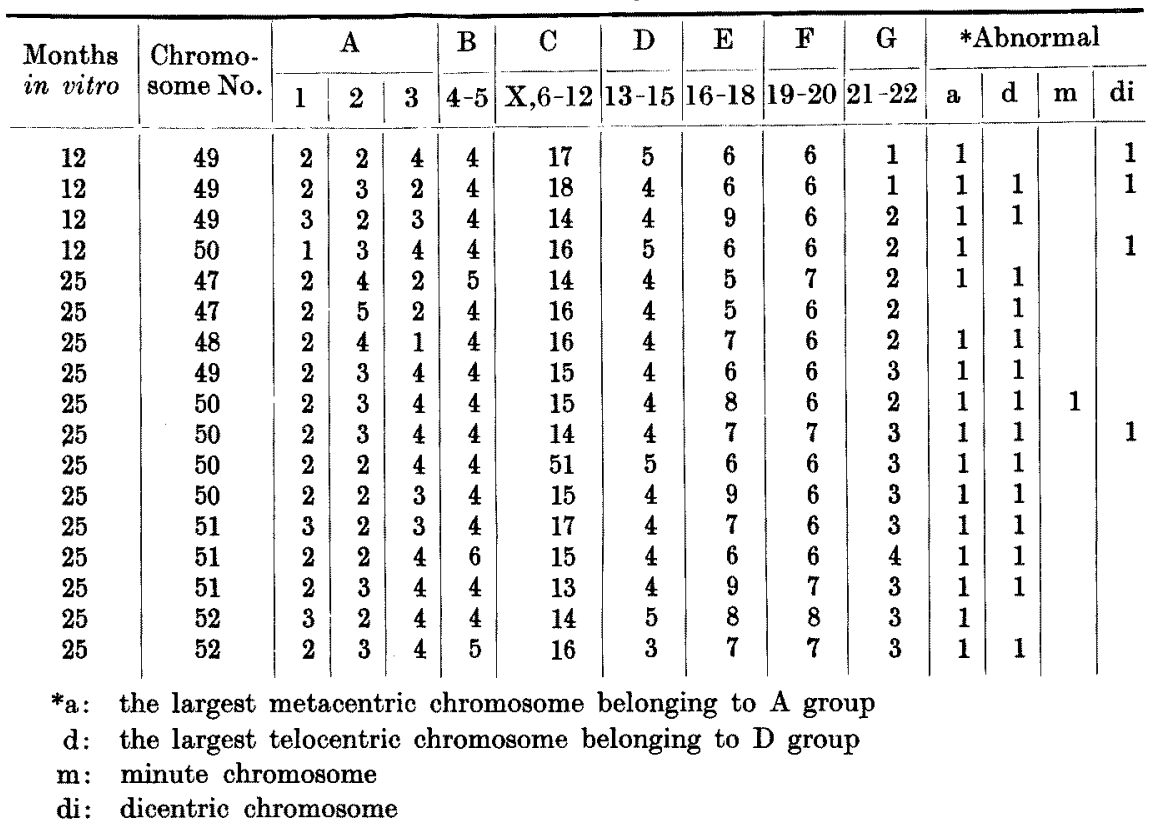

Transplantation test: Following Folley and Handler's method, the cheek pouches of one-month-old cortisone-treated Syrian hamsters were implanted with $10^{6}, 10^{5}$ and $10^{4}$ cells after 20 months in vitro, respectively. Two weeks after the implantation the nodules of 1 to $2 \mathrm{~mm}$ in diameter were observed in the hamsters which were implanted with $10^{6}$ cells. For one month thereafter the growth of the nodules was checked, while the animals were emaciated. So the nodules were resected and examined histologically. The center of the nodules showed necrosis and in the peripheral part, aggregated growth of some special cells was observed which did not exist in the normal hamster's cheek pouch and would have originated from the cultured cells (see Fig. 4). But the histological findings did not show any sign of invasiveness to the neighboring tissue, one of the characteristics of cancer cells. No nodule was observed in the hamsters implanted with $10^{4}$ cells, while nodule formation was observed in two of seven animals implanted with $10^{5}$ cells.

\section{DISCUSSION}

The authors cultured the cells from the explants of the specimen diagnosed as squamous cell carcinoma of human penis and successfully separated fibroblastic and epithelial cells from their mixture. But the fibroblastic cells ceased to exist 6 months after the culture initiation, while the epithelial cells could be maintained in vitro so far over 3 years. The morphology of the latter cells did not show any 
gross variation in spite of the long-term cultivation. The present cell line did not follow the typical establishment process of the cell line reported by many investigators. ${ }^{10.11}$ An electron-microscopical observation revealed many microvilli along the surface of the present cells. The presence of the microvilli, however, does not necessarily afford the evidence of the true epithelial cell. ${ }^{12}$ But the present cell line would be assumed to be of epithelial cell origin from the facts that it always indicated epithelial morphology and also pavement-like cell arrangement since its primary culture.

Ishihara et $a^{t} \cdot{ }^{13}$ examined the chromosumal distribution of 9 kinds of cell cultures which originated from human tumors and maintained them in vitro for a long time. Of those, 2 cultures had their modal distributions in the hyperdiploid range and they could not be established, while the remaining 7 cultures had their modal distributions in the triploid range and they were established. Auersperg and Hawryluk ${ }^{14}$ described that the modal distributions of the cultured cells originating from human cancers were in the hypodiploid range. Yamane and $\mathrm{Kusano}^{3}$ reported that the culture cells retained pseudo-diploid karyotype for a long time, which originated from the ascites cells of a case of reticulosarcomatosis and were cultivated in a suspension state. So the chromosomal distribution of the cells in vitro originating from human cancers would be variable according to the kinds of tumors and the cultural conditions. The cell population of the present cell line after 13 months in vitro showed bimodal distributions, one at 46 and the other at 52, and after the further cultivation they showed at first modal distribution at 52 only and later the further shift of modal distribution to 50. Anyhow, the modal distribution of the present cell line was kept in the hyperdiploid range. The karyotype analysis of the present cell line revealed the presence of 2 abnormal chromosomes which were maintained consistently unrelated to the culture period or total chromosomal number. They might be the so-called marker chromosomes. According to the reports by $\mathrm{Hsu}^{15-18}$ and many other workers, the major populations of the cultured cell lines were in the heteroploid range, whether they originated from normal or neoplastic cells. Therefore, even if the culture cells are of neoplastic cell origin, it is quite hazardous to predict the chromosomal constitution in vivo from that of their established cells in vitro.

Foley and Handler ${ }^{7}{ }^{8}$ reported that when culture cells were implanted into the cheek pouches of Syrian hamsters treated with cortisone, the cells of neoplastic cell origin could be differentiated from the cells of normal cell origin: $10^{3}$ cells in vitro originating from neoplastic cells could produce nodules in the cheek pouches of cortisone-treated hamsters, but the equal number of the cells originating from normal cells could not. In the case of the present cell line, however, $10^{5}$ cells could develop nodules in the cheek pouches of 2 in 7 hamsters tested, while $10^{4}$ cells could not produce nodules in any animal tested. The 
similar results were obtained in the authors' laboratory, using the established cells from a resected tissue specimen of human lung cancer. On the other hand, it has been demonstrated by many investigator ${ }^{19-27}$ that normal mammarian cells grown in vitro could undergo spontaneous malignant transformation after long-term cultivation. Therefore, it seems that the decision is very difficult whether the tested cell line is of neoplastic cell origin or normal cell origin on the basis of successful or unsuccessful nodule formation in heterotransplantation.

\section{References}

1) Gey, G.O., Coffman, W.D. \& Kubicek, M.T. Tissue culture studies of the proliferative capacity of cervical carcinoma and normal epithelium. Cancer Res., $1952,12,264-265$.

2) Kawashima, K. Establishment of a cell line in vitro from a case of human lung cancer. Sci. Rep. Res. Inst. Tohoku Univ. Ser. C, 1964, 11, 386-400.

3) Yamane, I. \& Kusano, T. Long-term cultivation of pseudodiploid cells of human tumor origin. Tohoku J. exp. Med., 1964, 84, 144-153.

4) Yamane, I. \& Tsuda, T. The collagen embedding culture of human cancer explants. Medicine and Biology (Jap.), 1963, 66, 46-49.

5) Niitsu, Y., Abe, S., Handa, T. \& Suetake, T. Streptomyces griseus protease used in tissue culture. Medicine and Biology (Jap.), 1963, 66, 174-178.

6) Rothfels, K.H. \& Siminovitch, L. An air-drying technique for flattening chromosomes in mammalian cells grown in vitro. Stain Techn., 1958, 33, 73-77.

7) Foley, G.E. \& Handler, A.H. Differentiation of "normal" and neoplastic cells maintained in tissue culture by implantation into normal hamsters. Proc. Soc. exp. Biol. Med. (N.Y.), 1957, 94, 661-664.

8) Handler, A.H. \& Foley, G.E. Growth of human epidermoid carcinomas (Strains KB and $\mathrm{HeLa}$ ) in hamsters from tissue culture inocula. Proc. Soc. exp. Biol. Med. (N.Y.), 1956, 91, 237-240.

9) Human chromosome study group. A proposed standard system of nomenclature of human mitotic chromosomes. J. Hered., 1960, 51, 213-221.

10) Hayflick, L. \& Moorhead, P.S. The serial cultivation of human diploid cell strains. Exp. Cell Res., 1961, 25, 585-621.

11) Todaro, G.T. \& Green, H. Quantitative studies of the growth of mouse embryo cells in culture and their development into established lines. J. Cell Biol., 1963, 17, 299-313.

12) Overman, J.R. \& Eiring, A.G. Electron microscope studies of intact epithelial and fibroblast cell surfaces. Proc. Soc. exp. Biol. Med. (N.Y.), 1961, 107, 812-816.

13) Ishihara, T., Moore, G.E. \& Sandberg, A.A. The in vitro chromosome constitution of cells from human tumors. Cancer Res., 1962, 22, 375-379.

14) Auersperg, N. \& Hawryluk, A.P. Chromosome observations on three epithelial cell cultures derived from carcinomas of the human cervix. J. nat. Cancer Inst., $1962,28,605-627$.

15) Hsu, T.C. Chromosomal evolution in cell populations. Int. Rev. Cytol., 1961, 12, $69-161$.

16) Hsu, T.C. \& Moorhead, P.S. Mammalian chromosomes in vitro. VII. Heteroploidy in human cell strains. J. nat. Cancer Inst., 1957, 18, 463-471.

17) Hsu, T.C., Pomerat, C.M. \& Moorhead, P.S. Mammalian chromosomes in vitro. VIII. Heteroploid transformation in the human cell strains Mayes. J. nat. Cancer Inst., 1957, 19, 867-873.

18) Hsu, T.C., Billen, D. \& Levan, A. Mammalian chromosomes in vitro. XV. 
Patterns of transformation. J. nat. Cancer Inst., 1961, 27, 515-541.

19) Gey, G.O. Cytological and cultural observations on transplantable rat sarcoma produced by inoculation of altered normal cells maintained in continuous culture. Cancer Res., 1941, 1, 737.

20) Earle, W.R. \& Nettleship, A. Production of malignancy in vitro. V. Results of injections of cultures into mice. J. nat. Cancer Inst., 1943, 4, 213-227.

21) Goldlbatt, H. \& Cameron, G. Induced malignancy in cells from rat myocardium subjected to intermittent anaerobiosis during long propagation in vitro. $J$. exp. Med., 1953, 97, 525-552.

22) Sanford, K.K., Earle, W.R., Shelton, E., Schilling, E., Duchesne, E.M., Likely, G.D. \& Becker, M.M. Production of malignancy in vitro. XII. Further transformations of mouse fibroblasts to sarcomatous cells. J. nat. Cancer Inst., 1950, 11, 351-375.

23) Evans, V.J., Hawkins, N.M., Westfall, B.B. \& Earle, W.R. Studies on culture lines derived from mouse liver parenchymatous cells grown in long-term tissue cultures. Cancer Res., 1958, 18, 261-266.

24) Moore, A.E., Southan, C.M. \& Sternberg, S.S Neoplastic changes developing in epithelial cells derived from normal persons. Science, 1956, 124, 127-129.

25) Leighton, J., Kline, I. \& Orr, H.C. Transformation of normal human fibroblasts into histologically malignant tissue in vitro. Science, 1956, 123, 502-503.

26) Barski, G. \& Cassingena, R. Malignant transformation in vitro of cells from C57BL mouse normal pulmonary tissue. J. nat. Cancer Inst., 1963, 30, 865-883.

27) Evans, V.J., Parker, G.A. \& Dunn, T.B. Neoplastic transformation in C3H mouse embryonic tissue in vitro determined by intraocular growth. I. Cells from chemically defined medium with and without serum supplement. J. nat. Cancer Inst., 1964, 32, $89-121$. 


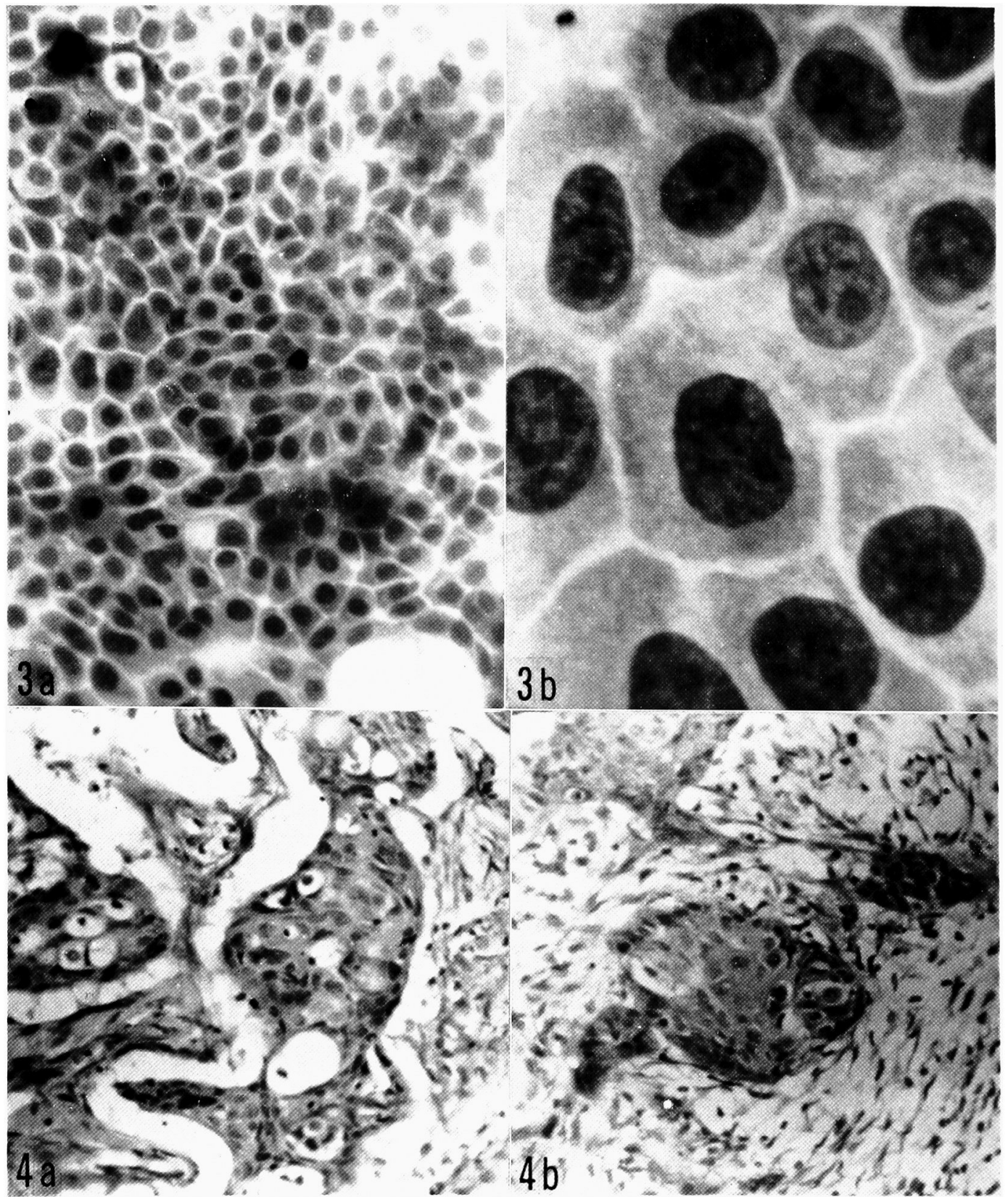

Fig. 3. PK cells stained with Giemsa.

a : $15 \times 20 . \quad$ b : $15 \times 90$

Fig. 4. The aggregated growth of the PK cells in the hamster's cheek pouch. a: $15 \times 20 . \quad$ b: $15 \times 20$ 


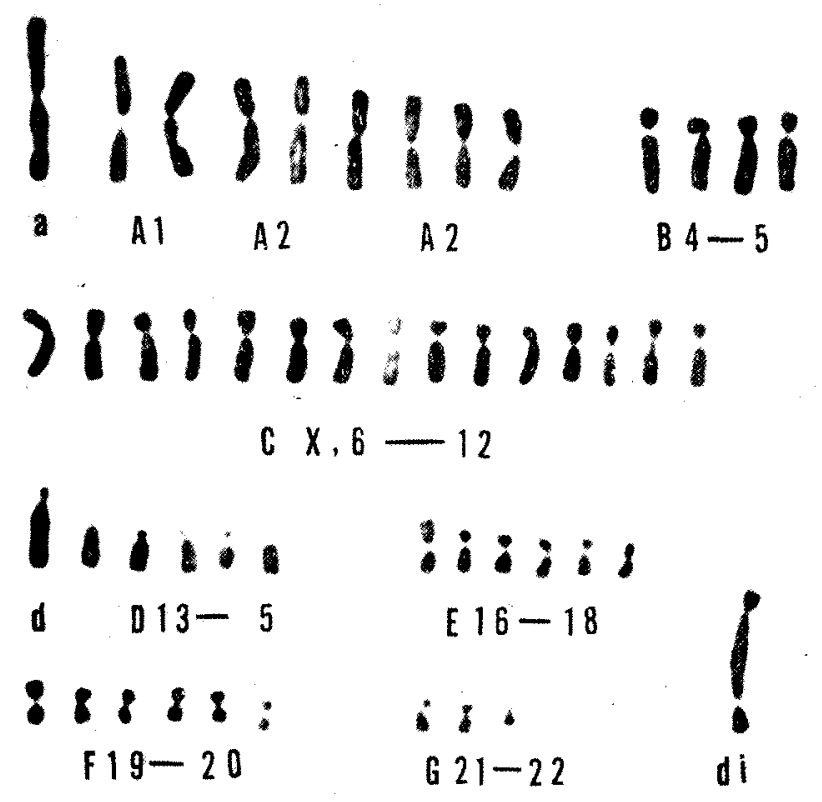

Fig. 5. Karyotype with 50 chromosomes.

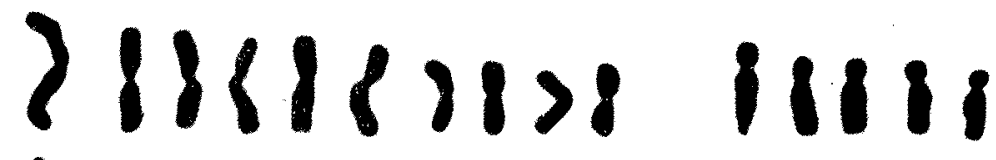 a $A 1 \quad A 2 \quad A 3 \quad$ B $4-5$

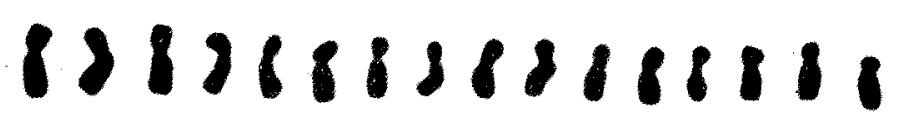 c $x, 6-12$}

$\begin{array}{ccc}1000 & 88088 \\ 013-15 & 16-18\end{array}$

$821 \% 1 \%$

F $19-20 \quad$ G $21-22$

Fig. 6. Karyotype with 52 chromosomes. 


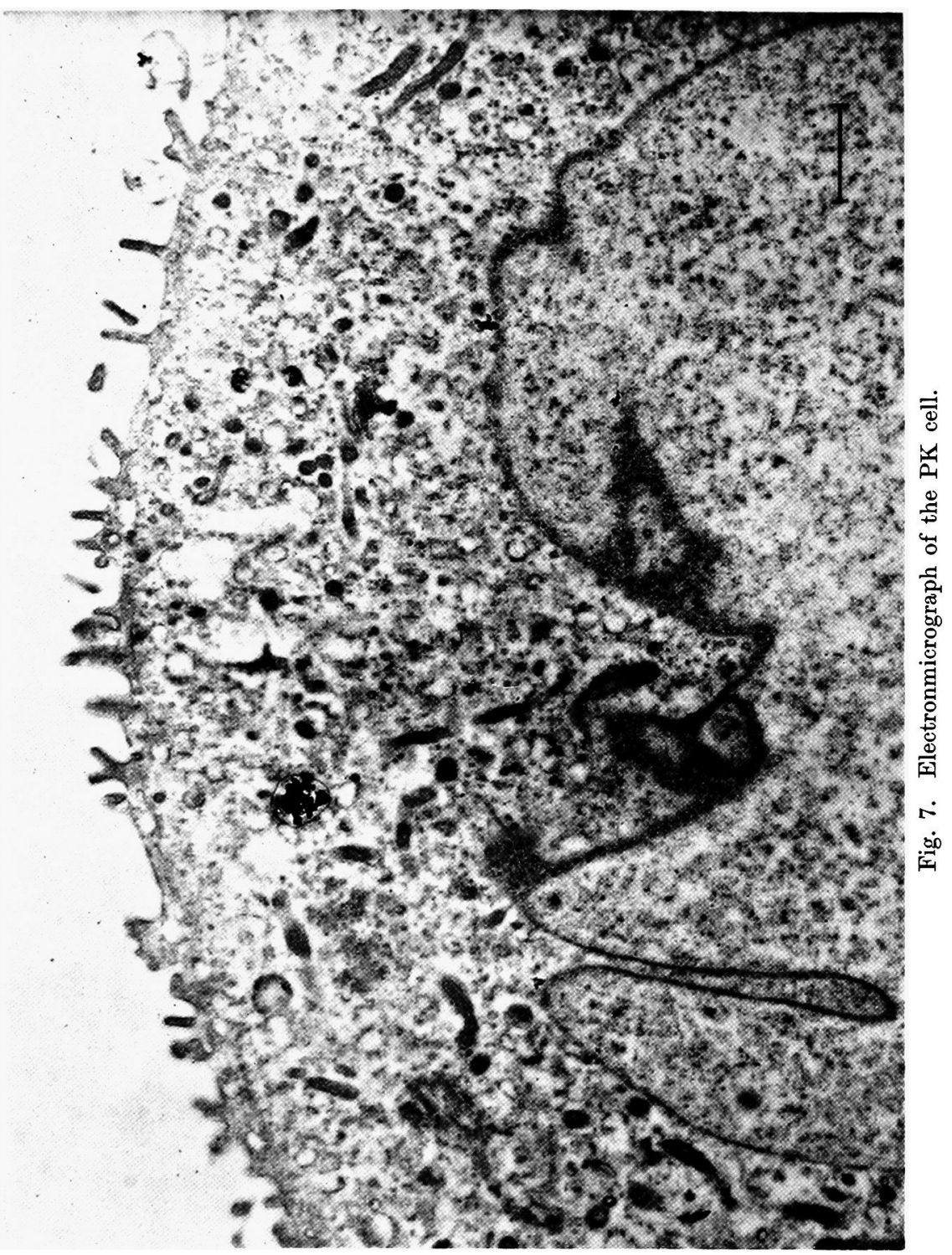

